\section{Original publications}

\author{
ALAN KERR
}

Editors of primary journals rely heavily on the integrity and judgement of authors submitting papers to them. However, coupled with this stance must be an awareness of the occasional fabrication of findings, plagiarism, gratuitous and ghost authorship and breaches of patient confidentiality.

Two further hazards, dual publication and dual submission, in which papers with identical or similar methods and data are published or submitted for publication in different journals, have been highlighted by the editors of the British Journal of Surgery (Williamson et al, 1993). Lock (1985) has commented that every editor can tell of examples where neither he nor the referee has detected that exactly or almost exactly the same work has already been published, without mention of this by the author. There are grounds for believing that duplicate publication is on the increase (Waldron, 1992) and attention has also been drawn to examples of triple publication of the same article (Holdsworth \& Crampin 1996; Shader \& Greenblatt, 1996).

In the field of psychiatry dual publication of a paper prompted the editors of the Acta Psychiatrica Scandinavica and the Journal of Clinical Psychiatry to publish a joint statement strongly urging authors to shun the practice (Gelenberg \& Ottosson, 1995). In the correspondence column of this issue of the British Journal of Psychia$t r y^{1}$ an allegation of possible duplication of publication is made together with a response by the authors concerned and an editorial comment.

An issue related to redundant publication is that of duplicate presentation of research findings at national meetings.
Cameron et al (1997) found that the duplication rate at selected national meetings attended by general surgeons was at least $15 \%$. They suggested, however, that it could be appropriate for research to be presented at regional meetings, with subsequent presentation of the same data at a national meeting.

The pressure on an author to strengthen his or her curriculum vitae is likely to be a driving force behind redundant publications and presentations, but a damaging consequence can be a clogging of databases and skewing of the literature in that field of study.

More difficult to decide on is the issue of overlapping or 'salami' publications. This occurs when the results of a large study are divided excessively among several smaller articles and distributed among several journals-general and specialist, national and international, local and regional (Lock, 1989). Assessments of such papers can be regarded as a matter of informed and delicate judgement along a continuum. This continuum extends from duplicate publications at one pole, through 'salami' publications and 'meat extender' articles (when, say, a few more patients are added to a series to give results and conclusions identical to those in the first publication (Lock, 1989)), through to the opposite pole where two or more papers from a single study contain sufficient original material and cross-citing to merit independent publication.

We share the sentiment expressed by the New England Journal of Medicine of wishing to continue to rely on the honesty and judgement of authors in informing us of any work of theirs that is related to the manuscript they are submitting for consideration (Kassirer \& Angell, 1995). The current 'Instructions to authors' (published in the January and July issues of the Journal) state that "The BJP publishes original work in all fields of psychiatry. ... Contributions are accepted for publication on the condition that their substance has not been published or submitted for publication elsewhere". If authors are at all uncertain about the potential for overlapping or duplicate publication, they should write to the editor for clarification enclosing a copy of other related papers ${ }^{2}$. Advice can then be given as to whether two or more of the papers would be more appropriately combined into a single paper, or whether there is sufficient original material and cross-referencing to merit multiple publication. In this way, we hope to retain the confidence of readers that the papers published are indeed original, that his or her time, and that of peer reviewers, is not being wasted and that scientific integrity is being protected.

\section{REFERENCES}

Cameron, I. C., Beard, J. D. \& Reed, M. W. R. (1997) Duplication of surgical research presentations. British Medical Journal, 344, 346-347.

Gelenberg, A. J. \& Ottosson, J.-O. (1995) Editorial statement. Acto Psychiatrica Scondinovico. 91. 145,

Holdsworth, G. \& Crampin, M. (1996) A

superabundance of evidence? Journal of the Royal Society of Medicine. 89. 299.

Kassirer, J. P. \& Angell, M. (1995) Redundant publication: a reminder. New England journal of Medicine, 333. 449-450.

Lock, S. (1985) A Difficult Balance. Editorial Peer Review in Medicine. London: Nuffield Provincial Hospitals Trust.

- (1989) Publication: duplicate. salami, meat extender all redundant. British Medical journol, 298, 1203-1204.

Shader, R. I. \& Greenblatt, D. J. (1996) Twice may be too many: redundant publications. Journol of Clinical Psychopharmocology. 16. I.

Waldron, T. (1992) Is duplicate publishing on the increase? British journal of Industrial Medicine, 304. 1029

Williamson, R. C. N., Farndon, J. R., Murie, J. A., et al (1997) Editors announcement. British Journal of Surgery, 314, 347.

2. See Editorial comment, p. 278 this issue 